\title{
Ciudadanías ciudadanas: un estudio exploratorio sobre representaciones sociales de la ciudadanía en Francia y Colombia
}

\author{
VALERIA AyOLA BETANCOURT*
}

\begin{abstract}
Artículo recibido: 5 de febrero de 2020
Artículo aprobado: 8 de mayo de 2021
\end{abstract}

Doi: https://doi.org/10.12804/revistas.urosario.edu.co/desafios/a.8680

Para citar este artículo: Ayola Betancourt, V. (2021). Ciudadanías ciudadanas: un estudio exploratorio sobre representaciones sociales de la ciudadanía en Francia y Colombia. Desafíos, 33(2), 1-38. https://doi.org/10.12804/revistas.urosario.edu.co/desafios/a.8680

\section{Resumen}

¿De qué manera los colombianos y franceses se representan la noción de ciudadania? El presente artículo es el producto de este amplio cuestionamiento, donde la noción de ciudadanía deja de ser estudiada en su dimensión normativa o formal, para ser interrogada desde las representaciones que suscita en los ciudadanos comunes. A través de un ejercicio de asociación de palabras y con la ayuda de la estadística textual, se comparan las representaciones de un grupo de franceses y colombianos sobre lo que significa la noción de ciudadania, en una encuesta exploratoria y no representativa. Los resultados resaltan la zona de consenso de la ciudadanía, a la vez que describen las particularidades encontradas entre los encuestados con relación a la nacionalidad declarada.

Palabras clave: ciudadania; representaciones sociales; Colombia; Francia; estadística textual.

* Ecole des Hautes Etudes en Sciences Sociales (EHESS - Paris) en cotutela con la Universidad Nacional de Colombia (Bogotá, Colombia). Correo electrónico: valeria.ayola@, ehess.fr. ORCID: http://orcid.org/0000-0002-4815-6368 


\title{
Citizen's Citizenships: An Exploratory Study of the Social Representations of Citizenship in France and Colombia
}

\begin{abstract}
How do Colombians and how do the French understand the notion of citizenship? This article seeks to answer this broad question, studying citizenship through the representations it arises in citizens themselves. Using data from an exploratory and non-representative survey, I compare the representations of a group of French and Colombian citizens of citzenship, through word association and an exercise in textual statistics. The results bighlight citizenship's consensus zone, while describing the particularities found among the respondents in relation to their declared nationality.
\end{abstract}

Keywords: Citizenship; Social representation; Colombia; France; Textual Statistics.

\section{Cidadania do cidadão: um estudo exploratório sobre as representações sociais da cidadania na França e na Colômbia}

\begin{abstract}
Resumo
De que maneira colombianos e franceses representam a noção de cidadania? Este artigo é produto desse amplo questionamento, onde a noção de cidadania deixa de ser estudada em sua dimensão normativa ou formal, para ser questionada a partir das representações que suscita nos cidadãos comuns. Por meio de um exercício de associação de palavras e com o auxílio da estatística textual, são comparadas as representações de um grupo de franceses e colombianos sobre o que significa a noção de cidadania, em uma pesquisa exploratória e não representativa. Os resultados evidenciam a área de consenso dos cidadãos, ao mesmo tempo que descrevem as particularidades encontradas entre os entrevistados em relação à nacionalidade declarada. Palavras-chave: cidadania; representações sociais; Colômbia; França; estatística textual.
\end{abstract}




\section{Introducción}

El presente artículo surge de una investigación exploratoria que buscó comprender las representaciones que se desprenden de la noción de ciudadanía en dos contextos particulares. ${ }^{1}$ Si bien la pregunta por la ciudadanía es un tema clásico para la ciencia política y el derecho, para esta investigación se adoptó una mirada interdisciplinaria con el fin de beneficiar el análisis de resultados y la orientación teórico-metodológica. Desde esta orientación, dejamos de preguntarnos qué es la ciudadanía o cómo se ejerce la ciudadanía en cierto contexto, para preguntarnos qué entienden por ello los sujetos investidos de esta condición en los Estados-nación contemporáneos. Lo anterior, con el propósito de arrojar nuevas luces sobre la manera en que los ciudadanos viven y se apropian del rol de sujetos políticos en los regímenes democráticos.

Más allá de lanzarnos en una cruzada normativa donde se persiga el ideal del ciudadano cívico -aquel que pueda enunciar características o recitar una definición de diccionario-, nos interesó verificar los sentidos que se desprenden de esta noción. Esto con el objetivo de proponer nuevos insumos para las investigaciones que se interesan en el estado y las transformaciones de las prácticas ciudadanas.

La perspectiva comparada, constituyó una entrada privilegiada para profundizar en aquello que es la ciudadanía realmente vivida y aprehendida por los ciudadanos ordinarios, ${ }^{2}$ conocidos en el lenguaje coloquial colombiano como los "ciudadanos de a pie".

La pregunta que detona esta investigación es, básicamente, descriptiva y exploratoria, ¿de qué manera los colombianos y los franceses se

\footnotetext{
1 Esta investigación fue expuesta en el coloquio "La Colombie aujourd'hui", bajo el título "Regards croisés sur les représentations ordinaires de la citoyenneté en France et en Colombie. Résultats d'une enquête exploratoire", llevado a cabo en la Universidad Paris 1 Panthéon-Sorbonne el 13 y 14 de octubre de 2017.

2 Término que retomamos de la investigación de Sophie Duchesne (1997) Ciudadanía a la francesa, este término nos permite hablar de personas que adquieren la ciudadanía por su nacionalidad, se refiere a las personas no politizadas y que, en un principio, se distanciarían de un discurso académico sobre la noción.
} 
representan la noción de ciudadanía? y, si estamos frente a un concepto universal de las democracias contemporáneas, ¿encuentra la noción de ciudadanía puntos en común entre estos contextos estudiados? Nuestra hipótesis de partida postula que a priori no existirían diferencias explicadas por la variación de los contextos si nos atamos a la universalidad de la noción.

En este artículo, primero, abordaremos los conceptos teóricos que guían la investigación; luego, revisaremos rápidamente algunas investigaciones empíricas que se han hecho desde perspectivas similares. Seguido de esto, procederemos a describir los detalles de la encuesta exploratoria realizada con ciudadanos de ambos países, así como la operación de procesamiento y tratamiento de los datos textuales. En la segunda parte del artículo, exponemos los resultados, aquello en que los sujetos de estudio coinciden y aquello que caracteriza a los encuestados en cada país.

\section{Marco teórico e investigaciones empíricas}

\section{Sobre la noción de ciudadanía}

Los estudios sobre ciudadanía, en general tratados desde la ciencia política y el derecho, han experimentado una apertura disciplinar a medida que la realidad política se ha complejizado en las democracias contemporáneas. Para la teoría política clásica, los individuos ceden el poder a la figura del soberano, el cual sella dicho pacto otorgando el estatus de ciudadano a los que, a partir de allí, se vuelven miembros de una comunidad política. Para Hobbes (2018), en un mundo en el que se dibuja con hombres que son lobos para los otros hombres, la cesión de la soberanía y el monopolio de la violencia se vuelve asunto vital para la seguridad de una comunidad que se perfile como política. Aun cuando no explicito, la ciudadanía implicaba ese pacto entre el soberano y los ciudadanos, el cual venía a renovar la antigua relación soberano-súbdito. Para Rousseau (2012), el contrato social implicaba que las voluntades individuales se sometieran a una voluntad general, regida por los principios de libertad y justicia. 
Una ficción política-social que daría la legitimidad teórica necesaria para la instauración de las repúblicas liberales modernas.

El enfoque contractual de la ciudadanía de Rousseau abre la modernidad política de occidente con un pacto social, que parte de la presunción formal de una igualdad jurídico-política que confiere derechos y deberes, es decir, un estatus a los miembros de una comunidad política dada. Con esto, la relación Estado-individuo se enviste de la mirada racionalista y contractualista propia de la modernidad, la cual vendría a dotar de un ideal político a los Estados-nación. En principio, la ciudadanía reposó sobre la prueba de la nacionalidad en un contexto de construcción de los Estados-nación y de los idearios de patriotismo e identidad nacional (Schnapper, 2017).

Entrado el siglo xx, los estudios del sociólogo T. H. Marshall delinearon la ciudadanía liberal como una progresión de un conjunto de derechos, producto de acuerdos y negociaciones entre los miembros y la autoridad estatal. Pero esta ciudadanía era vista, desde el ciudadano, como agente libre que se encuentra por encima de una idea de comunidad política. Son sus derechos los que definen su participación. De esta forma, de los derechos civiles declarados en el siglo XVIII, se sucede la extensión de los derechos políticos en el siglo XIX, para finalizar con los derechos sociales conquistados en el siglo XX. Para T. H. Marshall, los derechos sociales que los Estados de bienestar europeos recién conferían a sus ciudadanos, constituían el corazón de este nuevo modelo de ciudadanía, lo que, desde esta visión liberal terminaría por afectar en el largo plazo las desigualdades económicas gracias a su extensión y fortalecimiento (Marshall, 1950). Si nos atenemos a esta visión sustancialista de los derechos, el final del siglo XX y el siglo XXI verían la incorporación a los órdenes constitucionales de los derechos culturales, ambientales y sexuales. Esta es la ciudadanía liberal que ve a un sujeto que, gracias a su nacionalidad, se ve investido de derechos desde los cuales se reafirma ante la sociedad, generalmente desde una posición individualista.

La ciudadanía vendría, así, a ser el fundamento de la legitimidad racional de la que hablaba Weber, donde el poder se legitima gracias 


\section{6 / Valeria Ayola Betancourt}

a la existencia de un orden legal con un sistema coherente de reglas, implementadas gracias a la instauración de una burocracia (Weber, 1978, p. 217).

Con la idea republicana de la ciudadanía, se instaura la idea de civilidad o civismo como práctica; para Márquez, esto perseguía la regulación del orden social, amparada en las constituciones y en la idealización de la libertad, la igualdad, la propiedad y la soberanía de una "nación para los ciudadanos" (Márquez, 2011, p. 297). El ciudadano no solo cumple ciertos deberes, sino que también desarrolla ciertos comportamientos y prácticas que se confunden con una idea de urbanidad y civilización; esto por lo general, bajo un ejercicio de construcción de un ciudadano idealizado, en perjuicio de las identidades y culturas locales.

Cabe mencionar que la ciudadanía a la francesa tradicional estaría inspirada por la consigna republicana de la igualdad formal, donde el sujeto es un individuo abstracto que pertenece a una comunidad política, lo cual, si no rechaza, al menos invisibiliza la diferenciación étnico-racial, desplazada al orden de lo privado. Se trata de un sujeto que participa de una vida en común, donde sus derechos son la antesala a sus responsabilidades, los cuales se nutren de una educación moral y un ideal de comportamiento cívico (Schnapper, 2004). Este ha debido dialogar con los enfoques comunitaristas, que fueron determinantes en otros contextos como el estadounidense o canadiense, donde el ciudadano se concibe mucho más desde la óptica del reconocimiento y de su pertenencia a minorías étnicas, religiosas o grupos culturales, vitales en la participación a la vida política (Taylor, 1994).

Siguiendo a Dominique Schnapper, quien nos acerca a la reflexión francesa de la ciudadanía, esta sería la fuente de la legitimidad política pero también de la cohesión social de la "comunidad de ciudadanos" (Schnapper, 2000). Se trata de un ideal-tipo de vida en común, donde los derechos sociales son parte fundamental del ejercicio de la ciudadanía. Aun cuando hoy exista un desfase cada vez más grande entre los derechos formales y los reales, solo la igualdad real de sus miembros -reconocida por el Estado- y la garantía de ciertos dere- 
chos sociales, puede permitir el ejercicio de la práctica ciudadana en igualdad de condiciones (Schnapper, 2017). En esta línea, Paugam concibe la ciudadanía como un vínculo que es susceptible de brindar protección y reconocimiento al individuo, al otorgarle derechos que impiden su descalificación social. Un vínculo de ciudadanía fuerte implica un alto grado de confianza en las instituciones políticas y entre los ciudadanos (Paugam, 2008).

Por su parte, para entender caso colombiano, es necesario "asumir la construcción de la noción de ciudadano moderno, que emerge con la razón ilustrada, como una construcción discursiva, apoyada en el cuerpo constitucional y legal instaurado desde los inicios del orden republicano neogranadino en los albores del siglo XIX" (Márquez, 2011, p. 297). En ese entonces se sigue el orden republicano, el cual predomina sobre el liberal, con una ciudadanía restrictiva, basada en diferencias de género, clase y raza. Uribe propone el término "ciudadanía mestiza", la constitución de 1991 terminará inspirándose en las ideas comunitaristas al reconocer los derechos y participación de minorías (Uribe, 1998).

Para finalizar con esta sección, es importante recalcar que la historia de la ciudadanía lejos de ser neutra políticamente, hace parte de un relato construido por los Estado-nación dominantes en el proyecto de la modernidad europea, historia que evoca una representación heroica de la Grecia antigua, como lo recalca Engin Isin (2002 citado en Turmel, 2003). Para este autor, la historia de la ciudadanía fue escrita desde arriba por quienes de manera exclusiva ejercieron tal condición, lo cual ha impedido conocer como seres políticos a quienes no se encuentran en el poder (Isin, 2002).

Por esto, es importante reconocer que, en el contexto del proyecto de modernización de occidente, se erigieron modelos y principios de gobierno, que, luego son adoptados por las recién independizadas naciones del llamado nuevo mundo. Si nos atenemos a una perspectiva decolonial, el proyecto civilizatorio europeo encuentra en la transferencia de modelos de gobierno, la manera más eficiente de consolidar su hegemonía cultural, política, económica y simbólica 
(Quijano, 2000). Las incipientes naciones adoptaron unos marcos ajenos a sus contextos regionales desde una mirada eurocéntrica. Tener esto en cuenta, resulta determinante para esta investigación en dos contextos donde la variable histórica difiere.

Finalmente, concluimos este apartado teórico, recapitulando que la noción de ciudadanía es la representación del vínculo que tiene el ciudadano con sus pares y con el Estado, siendo el fundamento de la cesión del poder en los sistemas políticos contemporáneos. Este vínculo, genera reconocimiento dentro de una jurisdicción nacional y partiendo de este, a una internacional. Es una condición otorgada -aunque revocable- por igual a los mayores de edad, nacionales o naturalizados de un Estado soberano. Por un lado, se trata de un estatus, en la medida que es la condición necesaria para la atribución y exigibilidad de derechos, por lo tanto, de la protección. También es la condición que, permite la exigencia de obligaciones o deberes, en nombre de una comunidad política. Por otro lado, la ciudadanía es un proceso, evidenciable en ciertas prácticas, que tienen lugar en toda la vida política del ser humano. Aun cuando no existen grados de ciudadanía, existen desigualdades en el acceso a recursos, lo que merma las posibilidades de ejercerla efectivamente.

\section{La teoría de las representaciones sociales y nuevos enfoques del estudio de la ciudadanía}

Para esta investigación nuestro interés no está en la construcción política de la noción de ciudadanía, sino en la manera en que el término político es aprehendido y se ha asentado en el sentido común. Por esto, se buscó integrar una perspectiva teórica que permitiese dar sentido al estudio de las percepciones compartidas.

Siguiendo a Hannah Arendt, el estudio del sentido común tiene una importancia para quien se interese en el dominio público de la política y la moral, pues este engloba la conceptualización del pasado y aquello que hace tradición en un contexto. Esto, permite que los mundos particulares se acondicionen a un mundo social que se habita y comparte con los otros (Arendt, 2014). Más allá de la veracidad de 
dicho sentido común o de lo cercano o lejano que pueda estar, respecto a una definición del concepto, resulta interesante analizar el rol que cumple en la comunicación y en la cohesión de una sociedad, como herramienta de los individuos para encontrar sentido a la realidad social.

Uno de los enfoques que nos ha acercado al estudio del sentido común, es el de las representaciones sociales. Estas han sido estudiadas por los clásicos de la sociología como Émile Durkheim, quien identificó la existencia de conceptos comunes al grupo con valor de realidad concreta (Durkheim, 1968). Para él, las representaciones colectivas son el reflejo de la manera como la sociedad piensa su experiencia propia, y aun cuando no tienen autonomía de la experiencia de la realidad que las detona, su fijeza las transforma en objetividad. Por su parte, Max Weber considera las representaciones como vectores de la acción de los individuos, a través de estas se refleja la influencia de la sociedad en las prácticas y conductas (Weber, 1978).

El concepto de representaciones sociales fue utilizado inicialmente para referirse al rol de creencias o mitos en organizaciones tradicionales, las cuales hacían posible la unidad del grupo (Durkheim, 2004). En los años sesenta, el psicólogo social Serge Moscovici renueva el campo de estudio de las representaciones sociales, proyectándolas para grupos más grandes de población y teniendo en cuenta el impacto de la globalización y de las comunicaciones (Moscovici, 2003).

Para Denise Jodelet, quien sigue la vía de Moscovici, las representaciones serían modalidades compartidas:

El concepto de representación social designa una forma de conocimiento específico, el saber de sentido común, cuyos contenidos manifiestan la operación de procesos generativos y funcionales socialmente caracterizados. En sentido más amplio, designa una forma de pensamiento social. Las representaciones sociales constituyen modalidades de pensamiento práctico orientados hacia la comunicación, la comprensión y el dominio del entorno social, material e ideal. (Jodelet, 1986, pp. 474-475) 
Moscovici en sus trabajos sobre las representaciones del psicoanálisis, profundiza sobre la manera en que conceptos académicos, con una construcción científica e histórica dadas, son aprehendidos por un público no científico, teniendo en cuenta las transformaciones de las comunicaciones en un mundo globalizado y la manera en que se divulga el conocimiento (Moscovici, 2012). Las representaciones compartidas tendrían no solo una función cohesionadora para la sociedad, sino que además permitirían la comunicación entre los miembros de un determinado contexto cultural.

Para Jean Claude Abric, una representación social implica un conjunto organizado de informaciones, opiniones, actitudes y creencias a propósito de un objeto dado, estas son producidas socialmente y están fuertemente marcadas por los valores correspondientes al sistema socio-ideológico y a la historia del grupo que la utiliza, para quienes esta constituye un elemento esencial de su visión de mundo (Abric, 2005). Abric identifica que una representación se compone de un núcleo central, la zona "muda" y otra, periférica.

Recapitulando, las ciencias sociales han encontrado en el concepto de representaciones sociales una forma para denominar el proceso cognitivo mediante el cual los cuerpos sociales perciben y dan sentido a la realidad social, entiéndase, ciertos fenómenos, objetos, sujetos, nociones, etc. Estas pueden derivarse de aspectos presentes o ausentes de la vida en sociedad, pueden involucrar tanto temas novedosos como históricos, así como conceptos científicos divulgados. Estas permiten a las personas orientarse en su medio social, comunicarse con los otros y son determinantes para la cohesión del grupo.

\section{Nuevos enfoques en el estudio de la ciudadanía y objeto de estudio}

Ahora bien, esta investigación comparada busca trazos de las representaciones ancladas en el tejido cultural de ambas sociedades. Nos interesa analizar la representación social de la ciudadanía que en el contexto francés y colombiano se ha forjado, desde la perspectiva 
de las subjetividades políticas de los nacionales. La idea del Estado en sí reposa sobre un sistema de representaciones, compuesto por elementos que generan a su vez otros sistemas de representaciones, dentro de los cuales encontraríamos a la noción de ciudadanía. Entender lo que la abstracción de la ciudadanía genera en los individuos y en la dimensión de la vida, es decir, en lo biológico y lo biográfico (Fassin, 2018) es una tarea pendiente para las ciencias sociales y para la ciencia política en particular.

Esta opción teórica nos permite entender cómo cada sociedad ha configurado histórica y políticamente la relación con la institucionalidad y con los integrantes de la comunidad política a la cual adhieren. Este enfoque busca comprender la manera en que esto se materializa en la "cabeza de los hombres reales", como escribía Weber a propósito de las representaciones (Weber, 1978, p. 12).

Por otro lado, los estudios provenientes de la antropología de la ciudadanía o los citizen studies, entre los que resaltamos los trabajos de Catherine Neveu, nos han orientado en esta dirección. Neveu propone un cambio de paradigma hacia un estudio procesual y relacional de la ciudadanía, lo que significa involucrar los procesos de subjetivación política que enfrentan quienes se envisten de la calidad de ciudadano, lo cual incluye a ese sujeto ordinario, no necesariamente politizado (Neveu, 2013).

Este enfoque no viene a romper con el estudio formal de la ciudadanía, sino que sugiere por el contrario un diálogo con otras dimensiones que pueden enriquecerlo, como las dimensiones relacionales, sean de tipo vertical u horizontal; así como el estudio de la manera en que la ciudadanía es apropiada, reconstituida y reconfigurada tanto por los sujetos como por los actores institucionales (Neveu, 2013). La autora sugiere acercarse al estudio de la ciudadanía a través de métodos más próximos a los etnográficos, lo cual permitiría un cambio de perspectiva que dé profundidad al estudio de lo que Isin llama actos de ciudadanía, es decir, las prácticas concretas que delinean la subjetivación política de los sujetos (Isin, 2002). Esto para acercarse 
a la vivencia —más allá de lo formal— del ciudadano contemporáneo, es decir, a la parte más concreta del ejercicio y de la apropiación del poder, a través del estudio de prácticas políticas a nivel micro.

Isin nos invita a abandonar las definiciones abstractas y avanzar hacia el estudio de los actos ciudadanos de los grupos que se encuentran en puja con la institución (Isin, 2009). Siguiendo estos autores, la pregunta que se debe plantear no puede seguir siendo qué es la ciudadanía, sino aquello que los ciudadanos llaman ciudadanía, para de esta forma, avanzar hacia una concepción fluida y dinámica del concepto, la cual sea histórica y geográficamente válida (Neveu, 2013). Teniendo esto en cuenta, en la presente investigación exploratoria, nos propusimos un primer acercamiento al estudio de las representaciones sociales de la ciudadanía, a través del estudio de la manera en la cual el concepto ha sido reapropiado.

\section{Algunos estudios empíricos}

Teniendo la opción teórica clara, se emprendió una búsqueda de estudios empíricos con aplicaciones similares, encontrando una insuficiencia en los contextos estudiados, sobre todo para el caso colombiano y mayormente desde la perspectiva comparada.

Para el caso francés, una investigación nos sirvió de eje articulador para entender la manera cómo los franceses dotaban de significado la noción y el rol que le atribuyen. La investigación de Sophie Duchesne (1997), titulada Ciudadanía a la francesa, nos sirvió de esquema para entender en dicho contexto francés las formas de aprehensión por

parte de sus ciudadanos "ordinarios". ${ }^{3}$ Duchesne, a través de entrevistas no directivas, preguntó a diferentes grupos de la población qué significaba para ellos la noción de ciudadanía sin otra consigna o pregunta que esta. La investigación da cuenta de la existencia de

\footnotetext{
3 La autora estudió las representaciones de franceses que habían adquirido su nacionalidad por nacimiento, excluyendo los casos de naturalización o de residencia por parte de extranjeros.
} 
dos registros de interpretación bien marcados, lo que la lleva a proponer dos tipos ideales.

Por un lado, se encuentra lo que la autora denomina la ciudadanía por herencia, la cual es vivida como un compromiso con los valores de la nación, los cuales se preservan y se transmiten. En este registro, se ubicó el grupo de mayor edad, para quienes la ciudadanía se asocia a un estatus que se adquiere por nacer en dicho territorio, lo cual implica un respeto y un compromiso con los principios y valores de la nación. Esto coincide con la idea de la ciudadanía republicana. Por otro lado, la autora encuentra una visión muy diferente de la ciudadanía en la población más joven, visión que denomina ciudadanía por escrúpulos, en la cual los sujetos se perciben a sí mismos como atados a unos valores universales, como pueden ser los derechos humanos, a su vez que, perciben su rol como uno mucho más individual, que exige "hacer su parte" de la vida diaria. Estos adhieren mucho más frecuentemente a un ideal de "ciudadanos del mundo" atados no a los valores de una nación o de la nación francesa en particular sino a unos valores mundiales de igualdad y solidaridad, lo cual se acerca más a la ciudadanía liberal (Duchesne, 1997).

De particular interés resultó que Duchesne señalara en su estudio que "la asimilación de derechos y deberes, como definición de la ciudadanía, corresponde esencialmente a algo aprendido, a una expresión memorizada sin que sea necesariamente asociada a un contenido" (Duchesne, 1997, p. 260). Lo anterior, nos sirvió a la hora de analizar los resultados de la investigación exploratoria.

En cuanto a las investigaciones sobre la ciudadanía colombiana, se puede decir que en Colombia ha predominado el estudio de la ciudadanía desde una perspectiva normativa y, por lo general, en relación con la práctica electoral (González, 1997), ligada indiscutiblemente a una crisis de gobernabilidad y legitimidad (Medellín, 2003),estudiada en gran medida desde su relación con los mecanismos de participación ciudadana (González \& Velázquez, 2003) o a los movimientos sociales como forma de expresión ciudadana (Archila, 2001; Delgado, 
2007). Por otro lado, la ciudadanía ha sido analizada de manera desglosada por tipo de derecho.

A pesar de esto, los estudios poco se han centrado en los aspectos concretos y subjetivos de la vivencia de la ciudadanía, más allá del aspecto electoral y judicial. Por esto, postulamos que existe un desfase entre la vivencia de la ciudadanía y su estudio teórico, la academia no ha podido caracterizar aquello que sucede con la ciudadanía en el contexto colombiano, contexto caracterizado por bajo desempeño de la administración y la fragmentación territorial (García \& Revelo, 2018), donde la desigualdad socioeconómica condiciona el acceso diferenciado a los derechos y recursos socialmente valorados.

Para Villavicencio, lo que se ha dado en Latinoamérica es un quiebre de la ciudadanía formal en un contexto de mercantilización, lo cual condiciona el conjunto de derechos a la capacidad adquisitiva de sus miembros, generando una mezcla de democracia y exclusión. Esto conlleva a la autora a plantearse el sentido que adquiere la ciudadanía cuando los conciudadanos son en su mayoría personas que viven en la pobreza (Villavicencio, 2007).

En esta misma línea, cabe mencionar a Holston que, a partir del caso brasilero, se pregunta por el sentido del estudio formal de la ciudadanía en los países del llamado sur global. El autor reconoce una ciudadanía formal diferenciada, producto de arreglos históricos que privilegiaban a cierta parte de la población. Holston estudia las periferias en las ciudades brasileras, para darse cuenta de que otro tipo de ciudadanía era ejercida por sus habitantes, quienes a través de diferentes actos políticos no solo reclamaban, sino que ejercían otra forma de ciudadanía que poco a poco los integraba a la ciudad y a la formalidad (Holston, 2008).

Para el caso colombiano, han sido pocos los estudios empíricos que encontramos desde estos enfoques renovados de la ciudadanía, podemos mencionar el trabajo de Céspedes, quien desde una mirada psicosocial estudió la manera en que poblaciones específicas como los excombatientes y los reinsertados se representan el Estado y la 
ciudadanía (Céspedes, 2015). Los resultados hablan de diferentes registros de percepción ligados a la experiencia vivida, es interesante que este grupo de población concibe una ciudadanía basada en los derechos y se perciben como población prioritaria, donde el Estado adquiere un rol más bien paternalista.

También resulta interesante el trabajo de Henao y Pinilla, quienes estudiaron el significado de la ciudadanía y las prácticas derivadas para varios grupos de jóvenes, encontrando una tensión entre dos registros. Primero, uno que ve al Estado como represor y autoritario, el cual reduce a los jóvenes a la expresión del lenguaje coloquial "ciudadanos de segunda clase". Al mismo tiempo, estos se conciben como actores políticos con posibilidades de incidencia en el escenario político gracias a su consolidación activa en grupos y asociaciones de la sociedad civil. Esto último se asimila a la visión de los excombatientes, puesto que establecen relaciones paternalistas con los poderes públicos de una forma instrumental para acceder a recursos (Henao \& Pinilla, 2009).

En otro estudio interesante sobre las ciudadanías juveniles, Arias y Romero (2005) encuentran en los jóvenes una definición restrictiva de la ciudadanía y una amalgama entre lo que sería la ciudadanía civil, política y social. Les llama la atención la insistencia de una definición por referentes geográficos (ciudad), lo que estos consideran contribuye a despojar del sentido político a la noción. Basados en una encuesta, encuentran que los jóvenes manifiestan sentirse ciudadanos por vivir la ciudad, tener una cédula (nacionalidad) o cuando participan en actos patrióticos. Mencionan la preponderancia de la palabra derechos, lo que atribuyen al currículo escolar, que ha priorizado la socialización de la constitución política. Es interesante que los autores postulan la existencia de una definición emocional, en ciertos aspectos anclada al pasado y que privilegia los vínculos afectivos de primer orden, como los de la familia y del territorio. A su vez, identifican una asociación de lo ciudadano a lo adulto, a la idea de pertenecer y ser reconocido en grupos, alejados de la política tradicional. 


\section{Comparar como etapa preliminar del diseño de investigación: la encuesta Civitas Francia-Colombia}

La comparación es una estrategia analítica que ha quedado establecida en ciencia política con fines no solamente descriptivos sino también explicativos (Pérez, 2010). La comparación por casos es uno de los métodos más usados para tratar procesos macro dimensionales, donde se tiende a seleccionar casos paradigmáticos para explorar a fondo las características. Una selección de casos implica un manejo de variables similares y diferentes que permitan probar la hipótesis de la investigación. Este estudio se vale de la herramienta comparativa, pero solo de manera exploratoria, es decir, que da lugar a hipótesis que deben ser comprobadas posteriormente. Esto se efectuó porque el estudio de caso, aunque profundiza, no permite tan claramente entender lo singular, ni el impacto que las variaciones geográficas pueden tener.

Teniendo esto en cuenta, se toma el caso francés como caso paradigmático, el cual orienta y permite situar los resultados del caso colombiano. Tomarlo es importante en la medida que nos ilustra sobre una sociedad que acuñó las primeras teorías políticas, la declaración de los derechos humanos y la noción de ciudadanía en 1789. Donde instituciones como la escuela republicana, continúan modelando y transmitiendo la idea de una comunidad de ciudadanos. A su vez, se trata de una sociedad que, en la segunda parte del siglo XX, consolida una sociedad civil que logra incidir en el juego político.

Más allá de la variable histórica, el caso francés nos interpeló porque, a diferencia de otros países europeos, su régimen político es semipresidencial, de suerte que, este caso en el que el ejecutivo goza de amplios poderes, se vuelve más cercano y comparable con el caso americano. El caso estadounidense podría proporcionar pistas, sin embargo, su modelo de descentralización administrativa sesga la comparación. Por otra parte, la comparación con un país Latinoamericano de características similares podría revelar resultados menos interesantes. 
El caso colombiano es entonces diferente pero no opuesto, ya que guarda ciertas características que permiten el ejercicio, como por ejemplo la validez e inscripción en el acervo jurídico de ciertos aspectos inspirados del derecho francés. Asimismo, por la existencia de una tradición electoral que ha hecho a algunos considerar a Colombia como la democracia más antigua de América Latina -lo cual, si bien es debatible, no puede oscurecer el hecho electoral-. Además de la pertinencia de nociones como la de ciudadanía, Estado de derecho, así como los principios republicanos de libertad e igualdad.

Desde una perspectiva decolonial, resulta interesante entender las variaciones entre lo que podemos considerar un país "emisor" de representaciones políticas, desde una posición de hegemonía cultural e intelectual, y esto, compararlo con lo que podríamos denominar un país "receptor" de ideas políticas y de andamiajes institucionales.

Poner en la misma mesa a estos dos países resultó interesante puesto que desde sus regímenes políticos y configuraciones históricas diferentes, se exploró la existencia de un acervo común o representación colectiva, pero también se buscó actualizar el tema. De hecho, las democracias contemporáneas enfrentan diversos desafíos, entre los que se puede mencionar, la migración para el caso europeo y, la continua exclusión de una parte de su población, para el caso colombiano. Por todo eso, consideramos importante aterrizar lo que la noción de ciudadanía representa hoy en día, para quienes se envisten de la condición en diferentes partes del mundo occidental.

Finalmente, en un contexto de crecientes relaciones económicas y sociales entre estos dos Estados, estos resultados pueden ser de utilidad para entidades que trabajan en ambos contextos, por ejemplo, a nivel de proyectos de cooperación internacional pero también en relaciones jurídicas y comerciales.

Una vez escogidos los casos, se procedió a diseñar la encuesta, la cual, como ya fue expuesto, tuvo como objetivo ofrecer una primera lectura 
sobre las representaciones de la ciudadanía por parte de nacionales franceses y colombianos. Para esto, se realizó una encuesta exploratoria, no representativa estadísticamente. En la encuesta participaron 160 colombianos y franceses, los cuales se escogen aleatoriamente en una base de datos recolectadas en el sitio SurveyMonkey. ${ }^{4}$ Posteriormente, los datos fueron tratados con el software libre de tratamiento estadístico " $R$ " y con el paquete "Rtemis" de tratamiento de estadística textual.

Es importante mencionar que la encuesta se encuentra limitada en la medida que no permite extrapolar los resultados ni cruzarlos con las variables sociodemográficas que se pueden apreciar en la tabla 1. Las dos variables cruzadas que constituyen el análisis son solamente las de nacionalidad. A pesar de esto, se buscó una participación más o menos equivalente en términos de género y de niveles de estudio, tratándose en su mayoría de personas con un nivel de estudios superior al de bachillerato. Se entiende que el acceso virtual de la encuesta es otro de sus posibles sesgos por su accesibilidad, pero fue esto lo que permitió un trabajo de campo no presencial en dos países diferentes.

El sesgo posible en la representatividad se buscó contrarrestar con una sola pregunta clara y directa. La encuesta se compone de un ejercicio de asociación, donde a los encuestados se les pidió asociar un máximo de cinco palabras a la palabra ciudadanía, la cual aparece en letra grande en la pantalla. Luego de esto, los encuestados responden un breve cuestionario socio demográfico que recupera datos como rango de edad, género, formación educativa, etc. Los resultados fueron anonimizados.

4 Accesible vía: https://fr.surveymonkey.com/ 
Tabla 1. Características sociodemográficas de la muestra N:160

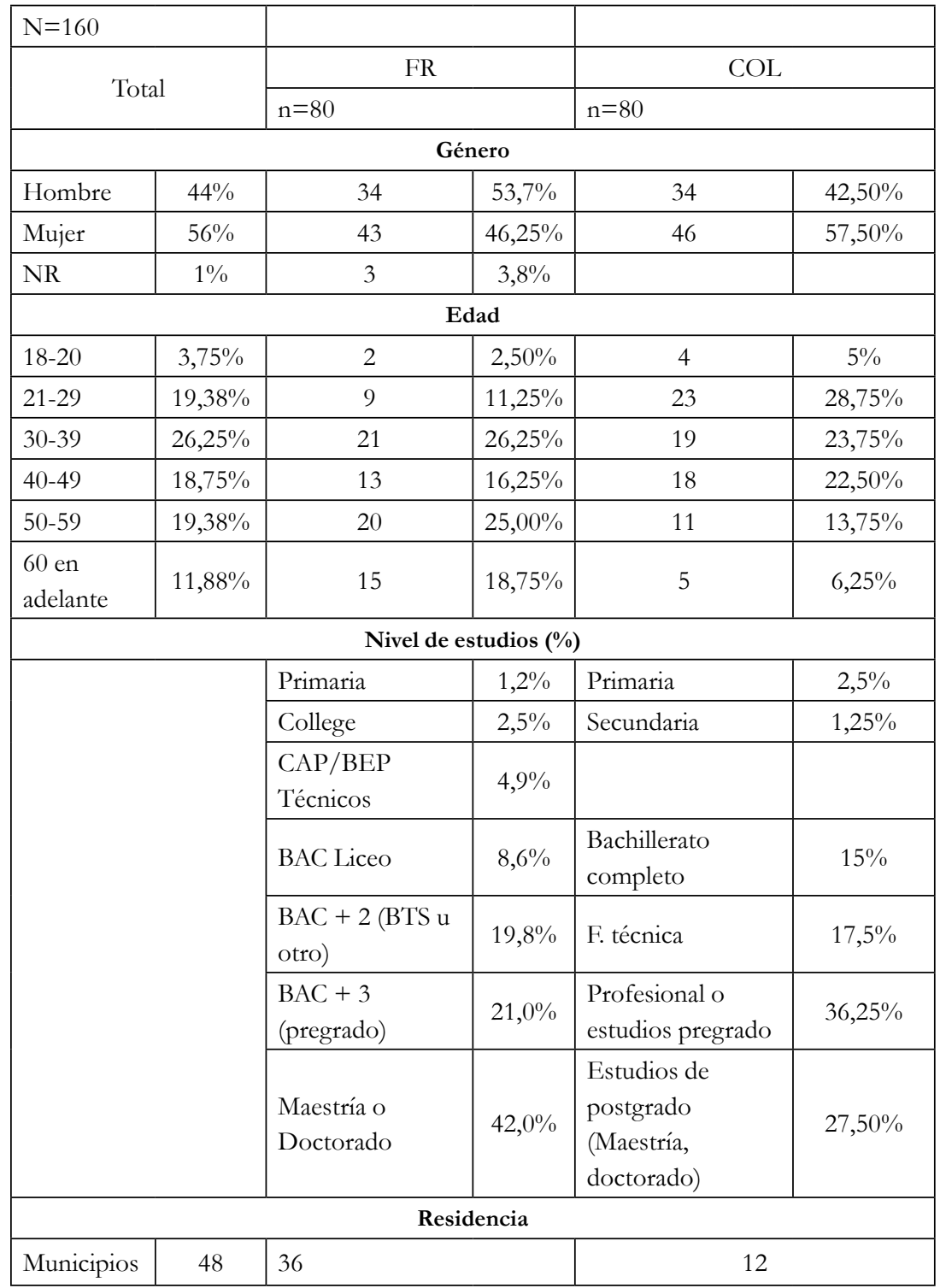

Fuente: elaboración propia con base en datos sociodemográficos recolectados en encuesta Civitas France-Colombie 2017.

El método de asociación de palabras se inspira en el trabajo de un grupo de geógrafos, quienes dan cuenta del interés de este tipo de métodos para la comprensión de la percepción colectiva. La estadística 
textual les ha permitido analizar diferentes representaciones como las asociadas a la palabra medioambiente (Guérin-Pace \& Collomb, 1998) o a la palabra Europa, por parte de estudiantes del mundo (Arnaud et al., 2013). Los resultados de estos estudios ratifican el interés de esta herramienta como método exploratorio para las ciencias sociales (Guérin-Pace, 1997) y también para el tratamiento de grandes volúmenes de texto. Este método que nos permitió llegar a las concepciones espontáneas, limitó la intervención del investigador, y al mismo tiempo, se reveló interesante para acotar un tema amplio.

Volviendo al resultado de la encuesta, se logró construir un corpus constituido por 959 palabras y 876 términos asociados, luego de esto, se procedió a la lematización de términos, lo que implica una operación de reducción del vocabulario por raíz, lo que nos permitió calcular los términos más frecuentes y los términos propios a cada variable. Cabe mencionar que la unidad de análisis es el término lematizado, donde cada una de las unidades es considerada de igual valor.

El corpus lexical inicialmente constituido por las 959 palabras se redujo a 876 términos luego de la supresión de términos vacíos (por ejemplo, pronombres), finalmente, 214 términos diferentes fueron los analizados, de los cuales $12,9 \%$ eran hapax o palabras que aparecieron una sola vez en el corpus.

Posteriormente, a través de un análisis factorial de correspondencias $(\mathrm{AFC})^{5}$ pudimos probar la hipótesis inicial de una diferencia en los contextos de estudio, gracias al cálculo del valor $t,{ }^{6}$ lo que nos permitió responder a la pregunta "quién dice qué" y realizar una representación gráfica del corpus. Esta operación también implicó hacer

\footnotetext{
5 Es una técnica descriptiva o exploratoria cuyo objetivo es resumir una gran cantidad de datos en un número reducido de dimensiones, con la menor pérdida de información posible. Su objetivo es similar al de los métodos factoriales, salvo que en el caso del análisis de correspondencias el método se aplica sobre variables categóricas u ordinales.

6 Se trata de un test estadístico que permite comparar los promedios de dos grupos muestrales, conceptualmente, el valor $\mathrm{T}$ representa el número de unidades estándares que están separando las medias de los dos grupos. Es utilizado para probar la independencia de las líneas y columnas de la tabla de contingencia.
} 
una clasificación del contenido del corpus por orden de aparición, lo que nos permitió identificar los términos más frecuentes por país, luego de lo cual pudimos obtener las palabras específicas para cada variable (nacionalidad) ${ }^{7}$

A continuación, presentaremos los resultados de la encuesta, primero describiremos los elementos y los diferentes registros de percepción identificados entre los encuestados, para luego, exponer lo que sería el tronco común de la ciudadanía, es decir, aquello en que los dos nacionales coinciden. Posteriormente, analizaremos cada una de las respuestas por país para finalmente esbozar una conclusión y el horizonte que los resultados dan para estudios más profundos en el área.

\section{Resultados generales}

El resultado de la encuesta nos permitió acercarnos a las diversas representaciones que tienen los dos grupos encuestados, se encontraron percepciones de tipo político-institucional, cultural y geográfico reagrupados en cuatro registros de percepción.

El primero ejemplifica la relación de los ciudadanos con el Estado e incluye en sentido amplio la relación con la institucionalidad. Encontramos aquí términos como derechos y deberes (D\&D), política, voto, república, democracia o administración. También fueron clasificadas aquí las palabras que aluden al sentimiento patriótico o nacionalista. Por último y desde una visión más pragmática fueron agrupadas aquí las palabras que se relacionaban con documentos de identidad, como pasaporte o para el caso colombiano cédula de ciudadanía.

\footnotetext{
7 Teniendo en cuenta que se trataba de una investigación exploratoria los datos socio demográficos no fueron tenidos en cuenta en el cálculo de la AFC sino como información adicional, ya que, por la poca representatividad de la muestra, no resultaba pertinente realizar cruces multifactoriales. Se controló la nacionalidad de los encuestados y su tendencia sociodemográfica es la de un nivel de estudio medio alto, con personas que en su mayoría completaron su bachillerato y persiguen estudios posteriores.
} 


\section{I Valeria Ayola Betancourt}

En el segundo registro encontramos aquel que asocia ciudadanía a la vida en sociedad y a los valores que permiten su regulación, aquí la ciudadanía deja de ser un estatus para convertirse en una especie de valor, un acuerdo colectivo donde el ciudadano adquiere un rol activo en la consecución de una vida en comunidad harmónica. La ciudadanía en este registro se parece mucho más a un proceso que se lleva a cabo de manera relacional, que a un estatus dado. La noción francesa del vivre-ensemble hace referencia al vivir en comunión con los otros, entre convivencia y coexistencia de los miembros, donde desde una ética republicana la idea de civilidad toma cuerpo. Este registro, hace más referencia a las relaciones que los individuos entretejen en sus contextos de hábitat, es uno que si bien implica un ideal de valores comunes también incluye unas reglas, acuerdos y actos que garanticen la calidad de vida. El ciudadano es entonces aquel que participa y realiza diferentes actos de compromiso, de respeto al otro y que adopta un comportamiento cívico. Reagrupamos aquí un conjunto de valores mencionados como el compromiso, el respeto al otro, la honestidad, el compartir o la tolerancia. Si bien esto está presente en los diferentes modelos de ciudadanía evoca particularmente al comunitarismo.

Luego, encontramos una definición que sugiere una ciudadanía como relación de pertenencia con un territorio dado, por tanto, sería la que cristaliza la territorialidad y el derecho de permanecer. Inducimos que es la persona biológica, no la ficción de un sujeto político lo que tiene lugar en esta representación. Por un lado, encontramos definiciones en términos de grupo humano como comunidad, sociedad, gente, personas, oriundo. Por otro lado, encontramos las definiciones geográficas como país, territorio, ciudad, lugareños, lugar. Nuestra interpretación es que la ciudadanía se concibe desde este registro no como estatus ni como proceso, sino como si el ciudadano fuera aquel que pertenece, habita y se relaciona con un lugar. Encontramos aquí una trasposición entre el concepto de ciudadanía y el de nacionalidad a escala local.

Por último, encontramos una definición de la ciudadanía en términos culturales, es decir, la ciudadanía como reservorio de la cultura, 
civismo e identidad de un grupo humano. En este registro encontramos palabras como: cultura, identidad, costumbres, civilización, modales, idiosincrasia. Identificamos aquí el proyecto civilizatorio que se realiza en nombre de la ciudadanía, sobre todo republicana. Es esto parte de la construcción de la nación mestiza latinoamericana que replica el modelo colonial e imperial, que oponía el civilizado al salvaje (Strauss, 2001). Ser ciudadano, se remite entonces a un criterio moral asociado a la figura del buen ciudadano, pero también implicaría un factor de exclusión para quienes no comparten o practican ciertos comportamientos considerados dentro de una construcción cultural hegemónica.

Estos cuatro registros identificados en el corpus permiten concebir las diferentes formas de pensar la ciudadanía por parte de nuestros encuestados. Cabe mencionar que la mayoría de las respuestas tuvieron una connotación positiva, lo que nos permite postular que los encuestados proyectan a través del ejercicio su posicionamiento normativo, aquello que "debería ser" la ciudadanía. En efecto, palabras peyorativas aparecen muy poco en el corpus, pues lo hacen en forma de hápax, de estas podemos mencionar las palabras exclusión, caos, desigualdad, ideal y moralismo.

El tronco común de la ciudadanía o la zona de consenso de la ciudadanía

Tabla 2. Términos más frecuentes. $\mathbf{N}: \mathbf{2 0}$

\begin{tabular}{|l|c|c|c|c|}
\hline \multirow{2}{*}{ Término raíz } & \multirow{2}{*}{ Ocu. global } & \multirow{2}{*}{ \% Ocu, global } & COL & FR \\
\cline { 4 - 5 } & & & \%mod/term & \% \\
\hline derechod & 52 & $6,0 \%$ & $56 \%$ & $44 \%$ \\
\hline deber & 36 & $4,1 \%$ & $36 \%$ & $64 \%$ \\
\hline respe & 32 & $3,7 \%$ & $6 \%$ & $94 \%$ \\
\hline comunid & 29 & $3,3 \%$ & $62 \%$ & $38 \%$ \\
\hline nacion & 25 & $2,9 \%$ & $56 \%$ & $44 \%$ \\
\hline respons & 23 & $2,6 \%$ & $22 \%$ & $78 \%$ \\
\hline pertenen & 21 & $2,4 \%$ & $67 \%$ & $33 \%$ \\
\hline ciudada & 21 & $2,4 \%$ & $76 \%$ & $24 \%$ \\
\hline
\end{tabular}




\begin{tabular}{|l|c|c|c|c|}
\hline \multirow{2}{*}{ Término raíz } & \multirow{2}{*}{ Ocu. global } & \multirow{2}{*}{ \% Ocu, global } & COL & FR \\
\cline { 4 - 5 } & & & \%mod/term & \% mod/term \\
\hline persona & 21 & $2,4 \%$ & $100 \%$ & $0 \%$ \\
\hline ciudad & 20 & $2,3 \%$ & $90 \%$ & $10 \%$ \\
\hline socieda & 18 & $2,1 \%$ & $78 \%$ & $22 \%$ \\
\hline particip & 16 & $1,8 \%$ & $44 \%$ & $56 \%$ \\
\hline politi & 16 & $1,8 \%$ & $75 \%$ & $25 \%$ \\
\hline voto & 16 & $1,8 \%$ & $81 \%$ & $19 \%$ \\
\hline juntos & 15 & $1,7 \%$ & $87 \%$ & $13 \%$ \\
\hline comparti & 14 & $1,6 \%$ & $21 \%$ & $79 \%$ \\
\hline pais & 14 & $1,6 \%$ & $71 \%$ & $29 \%$ \\
\hline ID & 12 & $1,4 \%$ & $92 \%$ & $8 \%$ \\
\hline solida & 12 & $1,4 \%$ & $75 \%$ & $25 \%$ \\
\hline ayud & 11 & $1,3 \%$ & $36 \%$ & $64 \%$ \\
\hline
\end{tabular}

Nota: veinte términos más frecuentes del corpus. El término raíz agrupa varios términos que comparten raíz, ej. politi: políticos, política, políticas, politiquería. ID reagrupa palabras con referencia a documentos de identificación. Fuente: cálculo del autor en Rtemis.

La tabla 2 nos muestra los veinte términos-raíz más frecuentes dentro de la muestra de estudio. Para nuestro análisis que busca proveer una interpretación común de la ciudadanía, escogimos los términos más frecuentes que aparecieran por lo menos en un tercio de la modalidad sobre término, para no sobredimensionar los términos que se tornan específicos de cada país. Es así como nos encontramos que la formula "derechos y deberes" representa un $10 \%$ del corpus, por tanto, es esta pareja de términos la que genera el mayor consenso entre los encuestados. Es importante su posición en el cálculo del AFC que se visualiza en la Figura 1, pues su centralidad nos habla de su cercanía con el encuestado promedio para ambas modalidades, aglutinándose alrededor de la primera dimensión.

Esto nos confirma el resultado de Duchesne en Francia, pues estas dos palabras parecen guiar la representación en ambos contextos. En la figura 1 puede observarse cómo las palabras en francés droit (derecho) y devoirs (deberes) son las más próximas al centro, las cuales de alguna forma concilian las palabras de ambas variables-país, el tamaño de los triángulos también nos advierte sobre la frecuencia de 
aparición de los términos. Es esta la representación dominante del individuo promedio de la encuesta.

Figura 1. Análisis de correspondencia con 25 términos

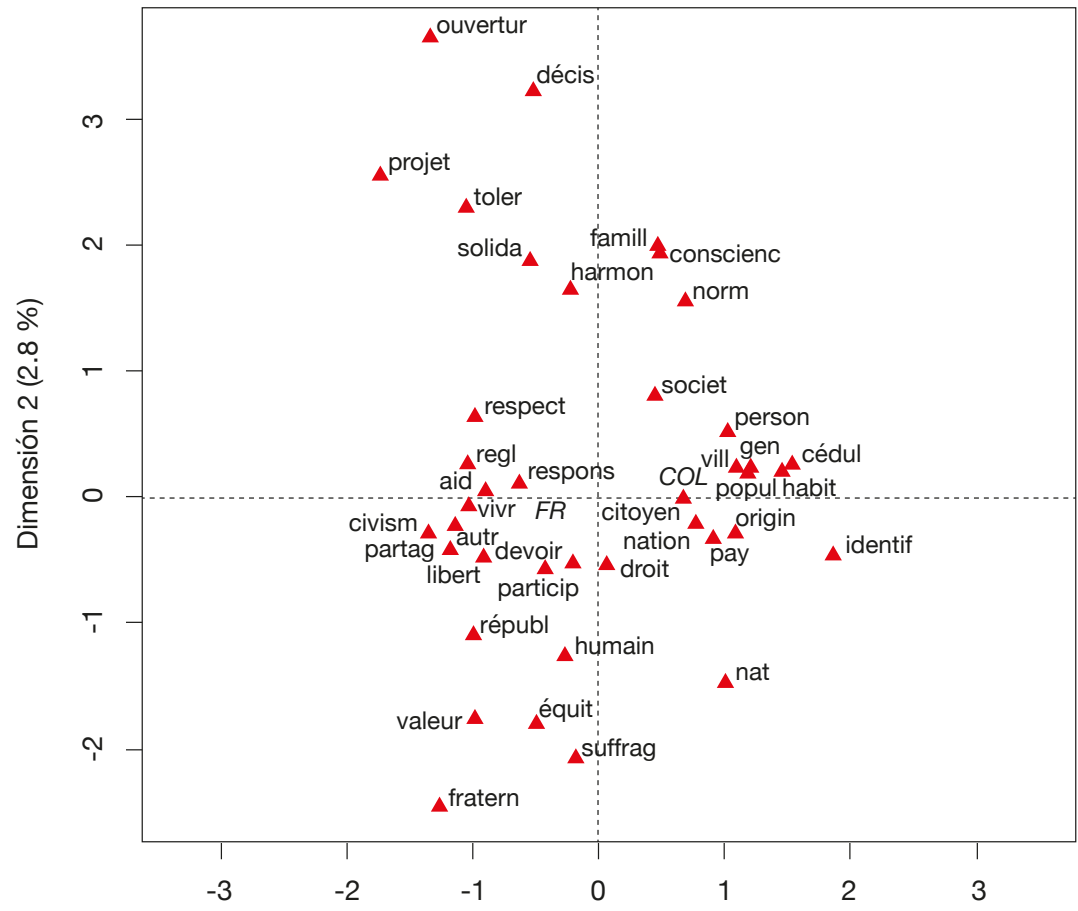

Dimensión 1 (3.1\%)

Fuente: cálculo del autor en Rtemis.

Luego, encontramos en el corpus la referencia a sujetos colectivos en diferentes niveles, en primer lugar, se encuentra comunidad (3,3\%), seguida por nación $(3 \%)$ por último, sociedad $(2,2 \%)$. Entre estos términos, aparece el término perten que, con un $2,4 \%$ de la modalidad, reagrupa pertenencia y pertenecer. La ciudadanía estaría asociada al hecho de pertenecer a una agrupación humana, sea comunitaria o nacional. Además de esto, la aparición de la palabra participa $(1,8 \%)$, que reagrupa participación, participativo(s), nos habla de una asimilación cada vez más importante de la ciudadanía con la dimensión participativa de la democracia. 


\section{6 / Valeria Ayola Betancourt}

Teniendo en cuenta estos resultados generales para ambos contextos nacionales, formulamos la hipótesis de que la ciudadanía encuentra un consenso en una interpretación que la asimila al hecho de pertenecer a una comunidad organizada donde se goza de derechos y contraen deberes. Duchesne en su investigación, nos advierte sobre el hecho de que esta relación de ciudadanía a derechos y deberes, puede corresponder a un lugar común sin tener necesariamente un contenido. Lo que vemos en el resultado es que los franceses se inclinan mucho más por una definición en término de deber, mientras que los colombianos se inclinan mucho más por una definición en término de derecho.

Seguido de esto, procedimos a identificar en el corpus las menciones a derechos y deberes concretos, escogiendo el derecho al voto o el sufragio para este ejercicio. Se encontró que, si bien los colombianos definen mucho más la ciudadanía en término de derechos, estos más difícilmente definieron derechos concretos en sus respuestas. Escogimos el derecho al voto como derecho concreto, encontrando que los franceses encuestados lo mencionaron en mayor medida que los colombianos, de hecho, de 16 veces que es mencionado el voto o el sufragio, 13 veces lo fue por parte del grupo de franceses. En cuanto a deberes concretos, estos fueron más difusos en las respuestas y obligaciones como la de pagar impuestos, la cual fue mencionada solo por franceses. Lo que también nos permite postular que los franceses conciben el deber no tanto ante el Estado como ante sus conciudadanos, lo cual exploraremos en el análisis específico a cada país.

En cuanto a los derechos sociales, estos tampoco aparecen casi en el corpus (2 Col y $1 \mathrm{Fr}$ ), lo que sorprende para el caso francés, donde el Estado de Bienestar de la postguerra enfatizó en el otorgamiento de una ciudadanía social. A pesar de esto, las palabras solidaridad y ayuda aparecen para el caso francés, lo cual da cuenta de una manera de denominar dicho régimen social. Para Colombia se esperaba una mayor mención de la constitución política de 1991 (dos veces) como marco legislativo de la ciudadanía.

A continuación, la tabla 3 reagrupa los resultados específicos para cada país, a partir de lo cual estableceremos los perfiles para cada variable. 
Tabla 3 Términos más frecuentes por país. $\mathrm{N}: 10$

\begin{tabular}{|c|c|c|c|c|c|c|}
\hline \multicolumn{7}{|c|}{$\$ C O L$} \\
\hline & $\begin{array}{c}\% \text { terme/ } \\
\text { mod }\end{array}$ & $\begin{array}{c}\% \text { mod./ } \\
\text { terme }\end{array}$ & $\begin{array}{c}\% \\
\text { global }\end{array}$ & Modalité & Global & Valeur $\mathrm{t}$ \\
\hline derecho & 6,2 & 56 & 5,9 & 29 & 52 & 0,19 \\
\hline persona & 4,5 & 100 & 2,4 & 21 & 21 & 4,66 \\
\hline comunid & 3,8 & 62 & 3,3 & 18 & 29 & 0,75 \\
\hline ciudad & 3,8 & 90 & 2,3 & 18 & 20 & 3,28 \\
\hline ciudadan & 3,4 & 76 & 2,4 & 16 & 21 & 1,92 \\
\hline nacion & 3,2 & 58 & 3,0 & 15 & 26 & 0,23 \\
\hline perten & 3,0 & 67 & 2,4 & 14 & 21 & 1 \\
\hline sociedad & 3,0 & 78 & 2,1 & 14 & 18 & 1,88 \\
\hline deber & 2,8 & 36 & 4,1 & 13 & 36 & $-1,97$ \\
\hline ID & 2,8 & 93 & 1,6 & 13 & 14 & 2,89 \\
\hline \multicolumn{7}{|c|}{$\$ F R$} \\
\hline & $\begin{array}{c}\text { \% terme/ } \\
\text { mod, }\end{array}$ & $\begin{array}{c}\% \text { mod./ } \\
\text { terme }\end{array}$ & $\begin{array}{c}\% \\
\text { global }\end{array}$ & Modalité & Global & Valeur $\mathrm{t}$ \\
\hline respeto & 7,4 & 94 & 3,7 & 30 & 32 & 5,62 \\
\hline deber & 5,7 & 64 & 4,1 & 23 & 36 & 1,97 \\
\hline derecho & 5,7 & 44 & 5,9 & 23 & 52 & $-0,19$ \\
\hline responsab & 4,4 & 82 & 2,5 & 18 & 22 & 3,21 \\
\hline juntos & 3,2 & 87 & 1,7 & 13 & 15 & 2,97 \\
\hline voto & 3,2 & 93 & 1,6 & 13 & 14 & 3,39 \\
\hline comunid & 2,7 & 38 & 3,3 & 11 & 29 & $-0,75$ \\
\hline nacion & 2,7 & 42 & 3,0 & 11 & 26 & $-0,23$ \\
\hline comparti & 2,7 & 79 & 1,6 & 11 & 14 & 2,18 \\
\hline civismo & 2,2 & 90 & 1,1 & 9 & 10 & 2,53 \\
\hline
\end{tabular}

Nota: los diez términos más frecuentes del corpus. Fuente: tabulación del autor del cálculo realizado en Rtemis.

Esta tabla plantea los términos más frecuentes para cada país, lo que podemos observar para el caso colombiano es que, si bien la palabra derecho resalta como sinónimo de ciudadanía, es notoria la frecuencia de la palabra persona(s), así como la de ciudad. Los colombianos encuestados también mencionaron las agrupaciones humanas, tales como comunidad, nación y sociedad. Igualmente, se destaca la aparición de los términos DI que reagrupan palabras referentes a documentos de identidad. 
Para el caso francés, se encuentran los términos respeto, responsabilidad, el "vivir juntos" y la expresión civismo, lo que nos hace proponer como hipótesis que los franceses encuestados ven en la ciudadanía como un asunto de compromiso hacia una comunidad o nación, lo que comulga con la idea republicana de la ciudadanía. Destaca también, el derecho al voto como término frecuente.

La figura 2 nos muestra el análisis de correspondencias simple con una sola una dimensión, la cual reagrupa los veinticinco términos más frecuentes y propios a cada variable país, donde los términos propios se ubican en los extremos de la línea.

Figura 2. AFC 25 términos

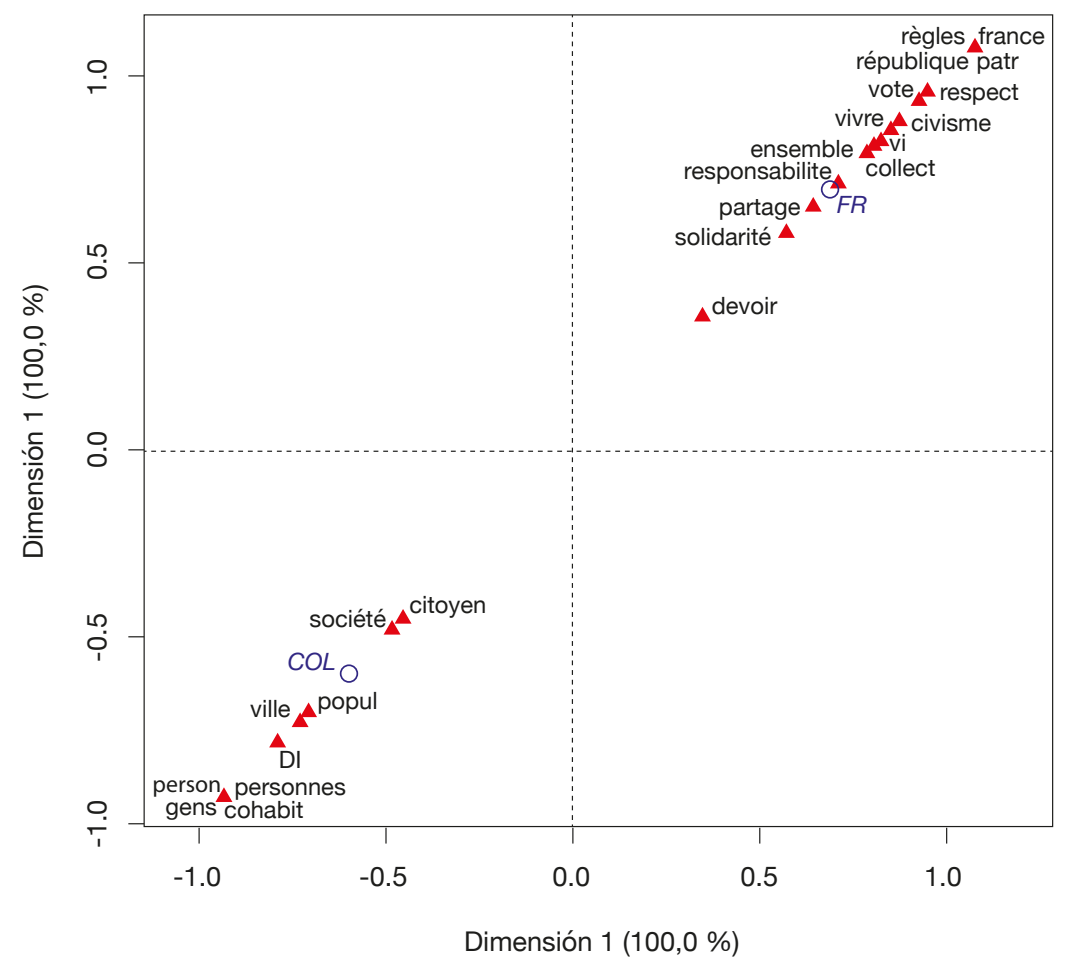

Fuente: cálculo del autor en Rtemis.

Los términos en que se encuentran las respuestas de los dos países son aquellos más cercanos al centro, sin embargo, en esta figura nos 
interesa la visualización de los más lejanos o propios a cada contexto. Para el caso francés encontramos que los términos más lejanos y específicos son Francia, república, reglas, patria, respeto, civismo, vivir juntos, responsabilidad y compartir. Para el caso colombiano encontramos los términos típicos como personas, pueblo, gente, convivencia, ciudad, población. De esta forma, se dilucidan los perfiles típicos o promedio para cada variable país.

El caso francés: "La ciudadanía designa un acuerdo colectivo de respeto a valores compartidos y del 'vivir-juntos'; el ciudadano se reconoce porque ejerce su derecho al voto"

Tabla 4. Términos específicos modalidad Francia

\begin{tabular}{|l|c|c|c|c|c|c|}
\hline & \% terme/mod. & $\%$ mod./terme & global & Modalité & Global & Valeur t \\
\hline respeto & 7,44 & 93,8 & 3,67 & 30 & 32 & 5,6 \\
\hline juntos & 3,23 & 86,7 & 1,72 & 13 & 15 & 3,0 \\
\hline responsa & 4,47 & 78,3 & 2,64 & 18 & 23 & 2,9 \\
\hline regla & 1,99 & 100,0 & 0,92 & 8 & 8 & 2,9 \\
\hline voto & 3,23 & 81,2 & 1,84 & 13 & 16 & 2,6 \\
\hline vivir & 1,99 & 88,9 & 1,03 & 8 & 9 & 2,3 \\
\hline comparti & 2,73 & 78,6 & 1,61 & 11 & 14 & 2,2 \\
\hline republic & 1,24 & 100,0 & 0,57 & 5 & 5 & 2,0 \\
\hline civismo & 1,74 & 87,5 & 0,92 & 7 & 8 & 2,0 \\
\hline vida & 1,74 & 87,5 & 0,92 & 7 & 8 & 2,0 \\
\hline deber & 5,71 & 63,9 & 4,13 & 23 & 36 & 2,0 \\
\hline
\end{tabular}

Nota: Los once términos propios a la modalidad Francia. Fuente: Cálculo del autor en Rtemis.

La preeminencia de la palabra deber y el análisis de los términos más frecuentes nos advirtieron de una disposición de los franceses encuestados a ver en la ciudadanía un asunto de compromiso cívico, de hecho, mencionaron el término respeto 30 veces, es decir $94 \%$ de las veces en que fue mencionada esta palabra. A partir de esto, la cuestión que se nos impuso fue la de averiguar cuál es ese objeto o sujeto de ese respeto y encontramos algunas pistas en el uso compartido de la palabra. Encontramos que la palabra compuesta fue 
utilizada para designar el respeto al otro, de las reglas, de la comunidad, de la nación, de los valores, del deber cívico y de la mayoría y la minoría. Los otros términos distintivos fueron responsabilidad (4to, 4,4\% mod), regla (5to, $1,9 \%$ mod) y civismo (6to, $1,96 \%$ mod). Lo que nos permite postular que los franceses no ven necesariamente en la ciudadanía una obligación ante el Estado (mención marginal al impuesto) y sí una ante sus conciudadanos o pares.

En la misma perspectiva, la expresión francesa del vivre ensemble, como término específico a la variable, nos permitió identificar más claramente ese pacto que constituye para los franceses la vida en comunidad, la cual se respeta y exige compromiso. La ciudadanía pasa entonces por el respeto de las normas y reglas que hacen posible la vida en sociedad (lo que incluye la ley), esto de alguna forma responsabiliza al ciudadano y a su vez, le otorga un lugar.

Por otro lado, el ejercicio de identificación de derechos concretos nos permitió ver que en Francia existe una asimilación más importante de la dimensión electoral, en tanto que elemento de la ciudadanía. De esta forma, los franceses logran diferenciar entre quién es y quién no es ciudadano. Esto tiene sentido en un contexto de afluencia migratoria hacia Europa y de un acceso diferenciado a un conjunto de derechos y garantías entre quienes gozan de la calidad de ciudadano, quienes son residentes autorizados y la situación de exclusión social que enfrentan los migrantes ilegales.

Finalmente, se encuentran términos propios al vocabulario relacionados con la historia nacional francesa, como los términos república, fraternidad, igualdad, solidaridad. En fin, por los elementos que disponemos, pudimos entonces formular como hipótesis que para los franceses "La ciudadanía designa un acuerdo colectivo de respeto a valores compartidos y del 'vivir-juntos'; el ciudadano se reconoce porque ejerce su derecho al voto”. 
El caso colombiano: "La ciudadanía designa a personas que pertenecen a una ciudad y viven en sociedad, se reconocen porque portan una cédula de ciudadanía"

Tabla 5. Términos específicos modalidad Colombia

\begin{tabular}{|l|c|c|l|c|c|c|}
\hline & \% terme/mod. & \% mod./terme & \% global & Modalité & Global & Valeur t \\
\hline persona & 4,4776 & 100,0 & 2,3973 & 21 & 21 & 4,7 \\
\hline ciudad & 3,838 & 90,0 & 2,2831 & 18 & 20 & 3,3 \\
\hline conviven & 1,7058 & 100,0 & 0,9132 & 8 & 8 & 2,5 \\
\hline gente & 1,7058 & 100,0 & 0,9132 & 8 & 8 & 2,5 \\
\hline pueblo & 1,7058 & 100,0 & 0,9132 & 8 & 8 & 2,5 \\
\hline habit & 1,4925 & 100,0 & 0,7991 & 7 & 7 & 2,2 \\
\hline cédula & 1,2793 & 100,0 & 0,6849 & 6 & 6 & 2,0 \\
\hline sociedad & 2,9851 & 77,8 & 2,0548 & 14 & 18 & 1,9 \\
\hline poblac & 1,7058 & 88,9 & 1,0274 & 8 & 9 & 1,9 \\
\hline Ciudada & 3,4115 & 72,7 & 2,5114 & 16 & 22 & 1,6 \\
\hline Politi & 2,5586 & 75,0 & 1,8265 & 12 & 16 & 1,5 \\
\hline
\end{tabular}

Nota: los once términos propios a la modalidad Colombia. Fuente: Cálculo del autor en Rtemis.

Entre los encuestados colombianos, la definición de la ciudadanía en términos humanos fue muy marcada, de hecho, los términos como persona, pueblo, población, habitante, hacen parte de los términos distintivos colombianos, los cuales están relacionados con referencias a términos geográficos que lo asocian a la pertenencia a un lugar, como coterráneo, gentilicio, lugareño, provinciano, pueblerino, ciudad. Estas dimensiones estarían marcadas por la vida en sociedad, pues no se trata solo de personas en un territorio sino de un grupo o conjunto que sobresale con el uso del término sociedad para el caso colombiano, muy por encima de términos como comunidad. Los colombianos también entreven en la ciudadanía, una relación con lo político, pues son en su mayoría quienes lo mencionan.

Llama la atención que en Colombia los ciudadanos son asimilados a lo que coloquialmente se conoce como la "gente del común", lo que incluso se encuentra explícitamente una de las respuestas. En este contexto, la ciudadanía se vuelve sinónimo de "gente" y de sociedad. El análisis de las respuestas nos llevó a postular como hipótesis que, 


\section{I Valeria Ayola Betancourt}

en Colombia el sujeto biológico - es decir la persona- se confunde con la abstracción jurídica que implica la noción de ciudadanía. El llamado a la "ciudadanía en general" puede leerse como implicando a menores de edad o extranjeros. No podemos descartar que esto tenga que ver con un abuso de la palabra entre los medios de comunicación, lo que nos remite al énfasis que Moscovici hace sobre estos, como determinantes del dinamismo de una representación social. Esto es interesante en la medida que, para el caso francés los términos humanos para referirse a la ciudadanía fueron inexistentes, como se puede observar en la tabla 5 en el porcentaje de ocurrencia por modalidad.

Ahora bien, mencionamos los términos geográficos como otro grupo de términos distintivos de los encuestados colombianos, de hecho, encontramos ciudad, como término propio a los colombianos (100\% mod.), así como los mencionados que hacen referencia a un arraigo espacial. Si bien el origen etimológico de la palabra ciudadanía hace referencia a la ciudad, esto nos permitió entrever cómo los colombianos asocian la ciudadanía a la vida urbana. Vemos en esto una hipótesis que no carece de lógica en un contexto histórico de dificultad estatal de control del territorio rural o, en general, extraurbano. Se trataría de una representación por oposición a la realidad rural del país.

Cabe mencionar de nuevo los trabajos de Isin, quien desde el contexto canadiense asocia el ejercicio de la ciudadanía, en primer lugar, a la ciudad, porque esta, en tanto que práctica social (la ciudadanía), es esencialmente urbana, pues es el espacio donde no solo tiene lugar la diferencia, sino también la innovación en prácticas ciudadanas (Isin, 2009). Sin embargo, esto desde la perspectiva de Holston es criticable, pues existen prácticas ciudadanas de la misma forma en los barrios ilegales como en el contexto rural, solo que con diferentes prácticas y métodos que aquellas utilizadas por el ciudadano formal urbano, clase media, blanco, es decir representante de lo normativo.

Volviendo a los resultados, se encontró otro término distintivo, cotidiano y a la vez interesante. Se trata del término cédula que correspondería a la cédula de ciudadanía colombiana, lo cual hace referencia al documento de identificación, que es prueba de nacionalidad y de 
ejercicio del derecho político electoral. En el corpus, reagrupamos los sinónimos como documento de identificación, identificación y pasaporte, bajo el nombre de documento de identificación (DI), esto para hacerlo comparable con las respuestas francesas. Se encontró que los franceses casi no hicieron esa relación de ciudadanía-documento, de las 14 veces en que aparece el término, solo una lo hace entre la muestra francesa y fue el pasaporte. Lo interesante de esto es que, si bien en Colombia la cédula porta el "apellido" de ciudadanía, lo que hace probable la relación, en el contexto francés, donde la migración y la legalidad impone una verdadera jerarquía entre sujetos, esto no sea mencionado.

La cédula es entonces el elemento material que prueba la pertenencia al territorio, la cual es prueba de identidad y permite el ejercicio de la actividad electoral, momento en el que se vuelve crucial su tenencia. Rápidamente podemos recordar que, por mucho tiempo los derechos políticos en Colombia fueron exclusivos de una parte de la población. Aun cuando Colombia mantuvo una tradición electoral, que jugó un papel fundamental en la conformación del Estado nación durante el siglo XIX (Bushnell, 1994), como nos recuerda Acuña "la cédula se convirtió más que en un documento de identificación, en un mecanismo para 'controlar' el fraude electoral' (Acuña, 2003, p. 30). En todo caso, lo que esta investigación nos sugiere es que la cedula de ciudadanía hace parte de la representación de la ciudadanía en Colombia, de una manera diferente a la tarjeta electoral en Francia o el documento nacional de identidad francés. ${ }^{8}$

Todos estos elementos encontrados nos permiten postular que en Colombia existe una apropiación mucho más pragmática del término ciudadanía, pues este es asociado a elementos tangibles como una cédula, una persona, una ciudad. Luego de haber analizado la representación francesa de la ciudadanía, la cual se basa mucho más en un ideal de vida en comunidad, vemos que la representación

\footnotetext{
8 Se trata de dos documentos diferentes en el contexto francés y solo recientemente es posible votar con el documento nacional de identidad en Francia, pero esto sigue siendo una excepción.
} 
colombiana de la ciudadanía aparece mucho más cercana, pragmática y tangible en comparación a los franceses.

\section{Conclusión y reflexiones finales}

La presente investigación de tipo exploratoria nos ha permitido obtener una primera radiografía sobre lo que los franceses y los colombianos piensan sobre la noción de ciudadanía. Ciertamente, el carácter no representativo de la población limita la extrapolación de los resultados a la totalidad de los contextos, a pesar de esto, logra proveernos un primer resultado que puede revelarse de alta utilidad no solo para quien se interese en el tema, desde una perspectiva comparada, sino para quien se interese en la particularidad de alguno de los casos. La hipótesis inicial se ve matizada ya que efectivamente se logra encontrar una zona de consenso donde se encuentran los nacionales de contextos tan diferentes como los tratados aquí. Por otro lado, el análisis de los términos frecuentes y propios nos muestra que existe una diferencia para nada insignificante. La ciudadanía tiene una connotación espacial y territorializada e incluso pragmática para los encuestados colombianos, mientras que para los franceses esta vehicula un deseo de vida en comunidad.

Con base en los resultados, postulamos que en Francia la ciudadanía refleja la relación de coexistencia en la esfera pública con el otro, donde el ciudadano es la representación abstracta de un sujeto con deberes ante la sociedad, sin importar su pertenencia étnica o regional. En Colombia, el ciudadano tendría menos aquel aspecto representativo y sería en mayor medida asociado a la persona biológica y a una territorialidad citadina.

Más allá de lo que los encuestados comparten, como el núcleo de la representación (derechos y deberes), la representación de la ciudadanía parece estar mucho más próxima a la vida cotidiana que a la de los textos normativos. La ausencia de una referencia a los derechos sociales en Francia o a los derechos constitucionales en Colombia, nos habla de un desfase entre el debate científico y el discurso ordinario. 
La dimensión estatal estaría presente en la medida en que estén en juego los derechos y deberes acordados.

Finalmente, la encuesta a pesar de sus límites logra dar algunas pistas sobre la manera en que los ciudadanos de los países del llamado sur global conciben su rol. Nuestro marco teórico y la revisión de estudios empíricos dieron cuenta de una insuficiencia de enfoques, estudiando la ciudadanía desde enfoques alternativos y desde una apertura disciplinar que entienda la subjetividad política como determinante del ejercicio político en las democracias contemporáneas. En suma, para esta investigación exploratoria, las herramientas cuantitativas se han revelado de extrema utilidad para obtener un primer acercamiento al objeto de estudio, mientras que la perspectiva comparativa nos permitió comprender lo particular a través de la diferencia.

\section{Referencias}

Abric, J. C. (2005). La recherche du noyau central et de la zone muette des représentations sociales. En J. C. Abric, Méthodes d'étude des représentations sociales (pp. 59-80). ERES. https:/ /www.cairn.info/methodes-d-etudedes-representations-sociales--9782749201238.htm

Acuña, O. (2003). Cédula de ciudadanía y documento electoral en Colombia. Revista Historia y Espacio, (20), 27-56.

Archila, M. (2001). Movimientos sociales, estado y democracia. Ponencia del Tercer Observatorio Sociopolitico y Cultural. Universidad Nacional de Colombia.

Arendt, H. (2014). Qu'est-ce que la politique? Edition du Seuil.

Arias, R., \& Romero, M. (2005). La ciudadanía no es como la pintan. Viento Sur Publicaciones.

Arnaud, B., Emsellem, K., Guérin-Pace, F., \& Garnier, B. (2013). Dire l'Europe à travers le monde. Cybergeo: European Journal of Geography, 630. https://doi.org/10.4000/cybergeo.25684

Bushnell, D. (1994). Las elecciones en Colombia: Siglo XIX, para bien o para mal las elecciones han sido una característica nacional. Credencial de Historia, (50).

Céspedes, S. (2015, enero-junio). Disposiciones, trayectorias e imaginarios sociales de Estado y ciudadanía en el proceso de reintegración de 
guerrilleros y paramilitares en Colombia. Revista Colombiana de Sociología, 38(1), 185-209. https://doi.org/10.15446/rcs.v38n1.53287

Delgado, R. (2007). Los marcos de acción colectiva y sus implicaciones culturales en la construcción de ciudadanía. Universitas Humanística, 64(64), pp. 41-66. https://revistas.javeriana.edu.co/index.php/ univhumanistica/article/view/2165

Duchesne, S. (1997). Citoyenneté à la française. Presses de Sciences Po.

Durkheim, E. (1898). Représentations individuelles et représentations collectives. Revue de métaphysique et de morale, 6, 273-302.

Durkheim, E. (1968). Les Formes élémentaires de la vie religieuse: le système totémique en Australie (1 ra ed. en francés, 1912). Presses Universitaires de France, PUF.

Durkheim, E. (2004). De la division du travail social. Presses Universitaires de France, PUF; Quadrige.

Fassin, D. (2018). La vie mode d'emploi critique. Seuil.

García, M., \& Revelo, J. (2018). El Estado en la periferia: Historias locales de debilidad institucional. Colección DeJusticia.

González, E., \& Velázquez, F. (2003). ¿Qué ha pasado con la participación ciudadana? Fundación Corona.

González, F. (1997). Legislación y comportamientos electorales: evolución histórica. En Para leer la politica, ensayos de historia politica colombiana. Cinep.

Guérin-Pace, F., \& Collomb, P. (1998). Les contours du mot environnement : enseignement de la statistique textuelle. L'Espace géographique, (1), 41-52.

Guérin-Pace, F. (1997). La statistique textuelle, un outil exploratoire dans les sciences sociales. Population, 52(4), 865-887. https://www.jstor. org/stable/1534617

Henao, J., \& Pinilla, V. (2009). Jóvenes y ciudadanías en Colombia: entre la politización social y la participación institucional. Revista Latinoamericana de Ciencias Sociales, Niñezy Juventud, 7(2), 1405-1437.

Hobbes, T. (2018). El Leviatán. Deusto.

Holston, J. (2008). Insurgent Citizenship. Princeton University Press.

Isin, E. (2002). Being Political. Genealogies of Citizenship. University of Minnesota Press.

Isin, E. (2009). La ville comme lieu du social. Rue Descartes, 1(63), 52-62. DOI: $10.3917 /$ rdes.063.0052

Jodelet, D. (1986). La representación social: fenómenos, conceptos y teoría. En S. Moscovici, Psicología Social II: Pensamiento y vida social. Paidós. 
Márquez, J. (2011). De vecinos a ciudadanos. Las estrategias políticas y culturales en el proceso de formación de la ciudadanía en Colombia: 1810-1860. Anuario de Historia Regionaly de las Fronteras, 16(1), 295-316. Marshall, T. (1950). Citizenship and Social Class and other essays. Cambridge University Press.

Medellín, P. (2003). Elementos de teoría y método para escrutar las crisis de gobernabilidad de América Latina. Estudios políticos, (22), 85-122.

Moscovici, S. (2003). Des représentations collectives aux représentations sociales: éléments pour une histoire. En D. Jodelet, Les représentations sociales (pp. 79-103). Presses Universitaires de France, PUF. https:// doi.org/10.937/puf.jodel.2003.01.0079

Moscovici, S. (2012). Raison et cultures. EHESS.

Neveu, C. (2013). «E pur si muove!», ou comment saisir empiriquement les processus de citoyenneté. Politix, 103(3), 205-222. https://doi. org/10.3917/pox.103.0205

Paugam, S. (2008). Le lien social. Presses Universitaires de France, PUF.

Paugam, S. (2016). La perception de la pauvreté sous l'angle de la théorie de l'attachement. Communications, 1(98), 125-46. https://doi.org/10.3917/ commu.098.0125

Pérez, A. (2015). El método comparativo: fundamentos y desarrollos recientes. En R. Castiglioni \& C. Fuentes, Política comparada sobre América Latina: Teorías, métodos y tópicos. Ediciones Universidad Diego Portales, UDP.

Quijano, A. (2000). Coloniality of Power and Eurocentrism in Latin America. International Sociology, 15(2), 215-232. https://doi. org/10.1177/0268580900015002005

Rousseau, J. J. (2012). Del contrato social. Alianza.

Schnapper, D. (2000). Qu'est-ce que la citoyenneté? Gallimard.

Schnapper, D. (2004). La République face aux communautarismes. Études, 2(2), 177-188. https://www.cairn.info/revue-etudes-2004-2-page-177. htm

Schnapper, D. (2017). Nationalité et citoyenneté. Pouvoirs, 160(1), 61-71. DOI $10.3917 /$ pouv.160.0061.

Strauss, L. (2001). El Pensamiento Salvaje. Fondo de Cultura Económica. Taylor, C. (1994). The politics of recognition. En A. Gutman (Ed.), Multiculturalism: examining the politics of recognition (pp. 25-73). Princeton University Press. 


\section{8 / Valeria Ayola Betancourt}

Turmel, P. (2003). Review Engin F. Isin, Being Political. Genealogies of Citizenship. Philosophiques, 30(1), 285-289. https://doi. org/10.7202/007750ar

Uribe, M. T. (1998). Órdenes complejos y ciudadanías mestizas: una mirada al caso colombiano. Estudios Políticos, (12), 25-46. https:/ / revistas.udea. edu.co/index.php/estudiospoliticos/article/view/16252

Villavicencio, S. (2007, julio-diciembre). Ciudadanía y civilidad: acerca del derecho a tener derechos. Colombia Internacional, (66), 36-51. http:// www.redalyc.org/articulo.oa?id=81206603

Weber, M. (1978). Economy and society. University of California Press. 